\title{
INFLUENCE OF SELECTED PHARMACOLOGICAL AGENTS ON THE PSYCHOPHYSICAL EFFICIENCY OF A HUMAN IN CONDITIONS OF THE EXTENDED ALERT PERIOD IN ASSOCIATION WITH THE HYPOXIA STIMULUS AT HIGH ALTITUDE
}

Anna PRZEWODZKA, Anna CZERWIŃSKA, Joanna ŁASZCZYŃSKA

Military Institute of Aviation Medicine, Warsaw, Poland

\begin{abstract}
Source of support: The paper was prepared as a part of the grant titled: "Improving the psychophysical fitness of a soldier during combat tasks by means of pharmacological stimulation." Contract no. 0042/R/T00/2009/08. The project was co-financed by the Ministry of Science and Higher Education.
\end{abstract}

Author's address: A. Przewodzka, Military Institute of Aviation Medicine, Krasińskiego 54/56 Street, 01-755 Warsaw, Poland, e-mail:aprzewo2@wiml.waw.pl

Introduction: The study was conducted to determine the effect of pharmacological agents - Vigil, Nivalin - on the psychophysical efficiency of a pilot in conditions of extended alert period in association with high altitude hypoxia stimulus.

Methods: The experimental group consisted of 13 men who were not acclimated to high altitudes. Within 24 hours before the experiment, the participants maintained a specific activity, which together with a unit study lasted 32 hours. The next day after receiving a single dose of the drug or placebo the men were exposed to simulated hypoxia conditions of $5000 \mathrm{~m}$ a.s.l. in a low pressure chamber. During the examination body temperature, heart rate, energy expenditure, sweat loss were controlled and subjective evaluation of the state of thermal comfort, the degree of nuisance of work and mood level were made.

Results: The longest time of hypoxia tolerance was recorded after administration of Vigil (Vigil $\mathrm{t}=523 \pm 128 \mathrm{sec}$, Nivalin $\mathrm{t}=443 \pm 200 \mathrm{sec}$, placebo $\mathrm{t}=241 \pm 225 \mathrm{sec}$ ). The percentage of people using an oxygen equipment was significantly lower after administration of psychostimulants (Vigil $=33 \%$, Nivalin $=42 \%$, placebo $=75 \%$ ). As a result of taking pharmacological agents, more favorable increases in core body temperature, energy expenditure and heart rate were recorded. Individuals receiving Vigil and Nivalin perceived the environment as more comfortable and indicated a significantly lower degree of nuisance of work

Figures: 11 • References: 34 • Full-text PDF: http://www.pjambp.com • Copyright @ 2018 Polish Aviation Medicine Society, ul. Krasińskiego 54/56, 01-755 Warsaw, license WIML • Indexation: Index Copernicus, Polish Ministry of Science and Higher Education 
in comparison with the control group. The level of mood (emotional tension) was more favorable after administering Vigil $(\triangle \mathrm{PN}=-14.58 \pm 6.66)$ and Nivalin $(\triangle \mathrm{PN}=-13.00 \pm 9.25)$ than placebo $(\triangle \mathrm{PN}=-11.41 \pm 9.82)$.

Conclusions: Vigil and Nivalin had a beneficial effect on human psychophysical efficiency (improvement of physiological parameters) during a prolonged period of alertness in combination with the stimulus of hypoxia. The medicines increased the body's tolerance to oxygen deficiency, significantly extending the time of exposure to hypoxia. Both substances (especially Vigil) improved subjective feelings of thermal comfort and the degree of nuisance of work and did not result in deterioration of mood.

Keywords: Vigil, Nivalin, psychoactive agents, nervous stimulats, high altitude hypoxia, thermal comfort, fatigue, workload

\section{INTRODUCTION}

A modern soldier is particularly exposed to excessive psychophysical strain manifested by both intellectual and physical fatigue [10]. An important determinant of deterioration of the psychophysical condition is the necessity to carry out sustained activities, shift work and increased levels of stress caused by high operational requirements carried out under time pressure [25]. Participation in stabilization missions or in the period of armed conflict is directly related to the extended time of duty (up to 35 hours and more) $[5,17,29]$, increased number of night flights and thus chronic sleep deficiency and intensification of fatigue symptoms $[6,7]$, which may be violent and unpredictable [17]. Maintaining vigilance and the cumulative effect of sleep deficiency, causing fatigue, increase the probability and frequency of symptoms of sleepiness, tiredness, short and uncontrolled naps among pilots, even during flight [14]. Moreover, the military nature of the currently undertaken air activities aimed at achieving the assumed objectives of the mission is related to the necessity of controlling modern high-maneuver machines, fighter planes such as MiG 29 and F-16. Operating this kind of aircraft entails the need for high and specific operator skills. They involve, among other things, the pilot's interaction with controls, including pilot-navigation devices (e.g. indicators, switches, controls), maintaining regular radio communications with the air traffic controller and other crew members, and observing the surroundings from the cabin. It is worth noting that activities in this area must be coordinated with the visual and auditory information received. This

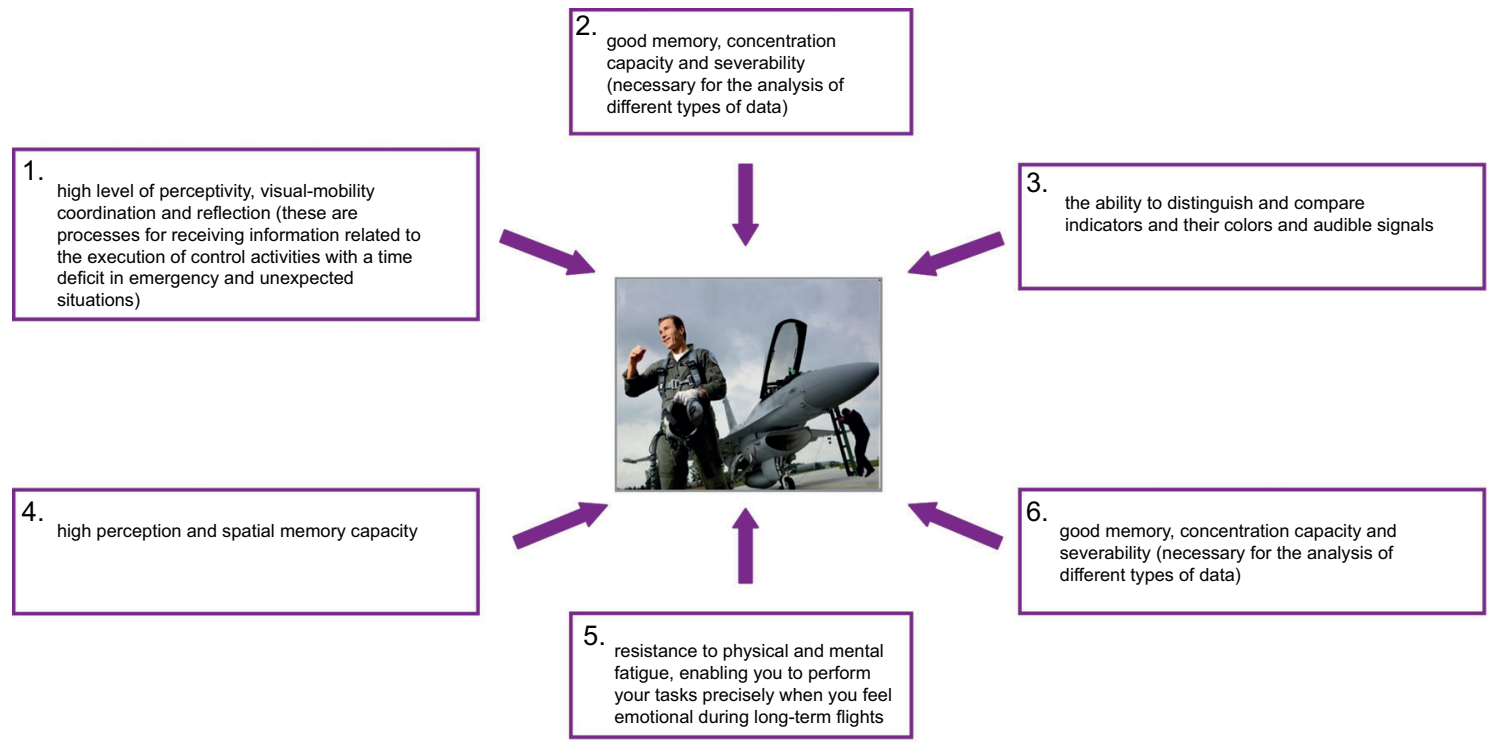

Fig. 1. Psychophysical properties of a pilot. 
is done by transferring attention from one instrument to another in an extremely fast and accurate manner. A pilot can sometimes spend as little as 0.5 seconds on a given instrument, which requires them to be able to transfer attention between signals up to 120 times in 60 seconds. In addition, the crew's ability to synchronize to ensure the smooth functioning of the entire system and the operation of the aircraft is essential. In order to effectively perform the flight operations that determine the full and satisfactory performance of the task, the safety and success of the mission in conditions of excessive service burden, many human psychophysical properties are needed (fig. 1) [17].

Long-term alertness is the cause of general fatigue. It is most often defined as an internal state of fatigue, characterized by reduced working capacity. Fatigue has a multi-directional nature and appears as a result of interaction between the requirements of the tasks, the conditions under which they are performed and the skills and perception of the operator [22]. Sometimes the notion of fatigue refers to subjective feelings, e.g.: bad mood or a reluctance to continue the task [31]. The lack of proper sleep hygiene combined with the worsening state of mental fatigue weaken the overall brain activity, which is the reason of decreased efficiency of a pilot during the missions [18]. The psychomotor and cognitive functions are reduced (disturbances in perception of the surroundings or slower information processing efficiency are observed) $[6,20,24]$. Most often, this is caused by the strain of concentration, the constant focus of the pilot on piloting operations and the situation in the air. Moreover, sleep deficiency may affect short-term memory, self-assessment of the level of alertness (necessary to safely continue the flight), limitation of analytical and abstract thinking, situation assessment, planning and decision-making skills, multi-directional thinking skills or verbal communication skills $[15,16,19,20]$.

The feeling of sleepiness, tiredness and reduced efficiency of the body are the most annoying during the night and in the morning (02.0005.00) due to the human circadian rhythm [23]. Disturbances of this cycle as a result of prolonged alertness contribute to the intensification of fatigue and reduced efficiency. Aviation personnel deprived of sleep loses approximately $25-30 \%$ of their intellectual capacity with each consecutive day of sleeplessness $[2,4]$. Recent studies conducted with the pilots of the F-117 bomber aircraft in a state of severe fatigue revealed that about 27-33 hours of duty without the opportunity to take a nap decreases the pilots' skills by over $40 \%$ below the initial level [8]. A detailed analysis of aviation accidents suggests that approximately $20 \%$ of them may be related to fatigue [28]. Thus, lack of sleep may result in the increase in dangerous aviation situations caused by the inability of aviation personnel to efficiently undertake proper operational activities [6].

One of the most important factors that deepen the state of fatigue and psychomotor efficiency is high altitude hypoxia or air hunger caused by oxygen deficiency in the body. Tolerance of high altitude hypoxia is varied individually, and also changes in terms of the circadian cycle. In the full compensation zone up to $3500 \mathrm{~m}$ above sea level, only increased activity of the cardiovascular system is observed, and the central nervous system maintains basic functions and efficiency mostly at an optimal level. People with weak adaptive mechanisms sometimes experience reduced physical capacity and memory problems. In the zone of incomplete compensation from 4000 to $6000 \mathrm{~m}$ a.s.l., disorders of most cognitive and motor processes are observed. The volume of lung ventilation increases rapidly due to accelerated and deepened breathing resulting from increased cardiovascular activity. As a result of deterioration of central nervous system functions, cognitive abilities are weakened. There are observed disturbances in operative and long-term memory, attention concentration, reduced decision-making ability and the level of coordination of precise movements (expressed as a greater tendency to make mistakes). Pilots usually find it difficult to read indications from on-board instruments, which is a result of abnormal functioning of the sense of sight (reduced contrast and visual acuity, image graying, reduced sensitivity to green and blue).

Acute hypoxia is particularly dangerous because it is characterized by the sudden exposure of the human organism to reduced partial oxygen pressure in the atmosphere or a reduced percentage of oxygen in the respiratory mixture. This, in turn, has an impact on the decrease in arterial blood saturation ( $\mathrm{SaO} 2)$. The risk of hypoxia occurs in an emergency situation, e.g. loss of cabin pressure, sudden damage to the oxygen equipment or exhaustion of the oxygen tank used by the pilot in an aircraft cabin without pressure protection. Acute hypoxia limits the body's ability to adapt and significantly shortens its survival time. The impairment of cognitive and mental functions caused by hypoxia may lead to symptoms of decompression sickness, which causes a whole range of functional disorders in organs and dam- 
ages to the tissue structure, to a degree depending on the duration of decompression, pressure difference or altitude.

During many hours of flight, the pilot experiences increasing levels of fatigue, sleepiness and irresistible need for sleep $[1,13]$. In situations when sleep is not possible, it is recommended to take stimulating pharmacological agents $[1,9,13,25]$. To optimize and increase the pilot performance, modafinil was approved for military use by the Air Forces of the USA, India, France, Singapore or the Canadian Space Agency [12,21,26,27,32]. Psychomotor tests have shown that Modafinil at a dose of $400 \mathrm{mg}$ has a comparable strength to $600 \mathrm{mg}$ of caffeine in limiting the loss of performance caused by fatigue. In addition, tests with lower doses of the drug have proven to be effective in maintaining alertness but for no longer than 24 hours. Modafinil has a longer half-life compared to caffeine (12-15 h vs. 4-6 h, respectively), thanks to which it maintains the suitable concentration in blood with a lower frequency of administration and reduces the risk of addiction [33,34]. Other studies carried out on a group of pilots (using 600 $\mathrm{mg}$ of modafinil administered in 3 doses of 200 mg each) indicate that Vigil (Modafinil) was able to maintain the performance during flight in the simulator for over $30 \mathrm{~h}$ without sleep [11]. These studies also revealed the occurrence of side effects of taking Modafinil (e.g. nausea, dizziness). The side effects can be eliminated by modifying the dosage and adjusting it to body weight. Administering pilots with an appropriate psychostimulant selected in terms of dose, duration of duty and time of day may help to mitigate or even eliminate the adverse effects of fatigue.

At present, there is a need to maximize the effectiveness of a soldier in combat conditions. In order to make more effective use of the pilot's abilities during long aviation tasks, attempts have been made to reduce the feeling of fatigue, increase the tolerance to high altitude hypoxia (5000 $\mathrm{m}$ a.s.l.) and thus increase the productive time through pharmacological support. The study was conducted to determine the effect of medicines - Vigil, Nivalin - on the psychophysical efficiency of a pilot in conditions of extended alert period in association with high altitude hypoxia stimulus. Improving knowledge of the effects of psychoactive agents on the performance and ability to perform aviation tasks in conditions of hypoxia may contribute to the modification of existing aviation procedures and training of future pilots of high-maneuver aircraft.

\section{MATERIAL AND METHODS}

\section{Preparation of drug doses}

Based on a thorough analysis of literature data on psychoactive substances approved in the European Union, two pharmacological agents: Vigil (Modafinil) produced by Torres Chiesi Polska Sp. z o.o. and Nivalin (Galantamine) by Janssen-Cilag Polska Sp. z o.o. were qualified for the research.

The drugs were administered in a single dose of $100 \mathrm{mg}$ of Vigil and 10mg of Nivalin. Psychostimulants looked like placebo pills (control), which contained a neutral substance, which in this case was lactose powder. The participants took the tablets whole (without biting), always at the same time (1 hour after a meal), with a glass of non-carbonated, low-mineralized water. A blind test method was used in the experiment in order to eliminate the effect of expectation of people on whom the substance is tested and to obtain an objective assessment of the effect of the medicines. The participants were randomly assigned to three groups.

\section{Properties of pharmacological agents}

The drug called Vigil (Modafinil) displays sympathomimetic properties with a central effect. It is an inhibitor of norepinephrine reuptake, which means an increase in neurotransmitter concentration in synaptic space. The drug was approved by the U.S. Food and Drug Administration (FDA) in 1998 in the treatment of excessive sleepiness in patients suffering from narcolepsy [3]. In the tests, Vigil has no euphoric effect, but it may potentially be addictive. Therefore, the development of addiction should not be completely ruled out, especially during long-term use. Vigil doses have a selective effect and cause clear activation in certain regions of the brain, especially in the hypothalamus as opposed to methylphenidate and amphetamine, which have comparable effects on alertness but increase overall brain neural activation. Vigil does not significantly increase the load on the cardiovascular system with respect to blood pressure and heart rate. In humans, Vigil maintains and (or) improves the quality and length of the state of alertness and the time of activity during the day in a dose-dependent manner. Pharmacological stimulation with Vigil counteracts impairment of cognitive, psychomotor and neurosensory functions caused by sleep deprivation. The agent does not cause any side effects on behavior or appetite. Among the most commonly reported side effects are: headache, fear, diarrhea, insomnia and anxiety, although not everyone will experience them. 
Nivalin is a drug containing galantamine, the active substance alkaloid, of plant origin, used in the treatment of diseases with synaptic transmission disorders (e.g. Alzheimer's disease). It belongs to the group of parasympathicomimetics with indirect effect. The drug reversibly inhibits the enzyme acetylcholinesterase (AChE), is a modulator of the nicotine receptor and increases the sensitivity of receptors to acetylcholine. By increasing the activity of the cholinergic system, it facilitates impulse conduction in neuromuscular endings. Galantamine facilitates signal conduction in the central nervous system due to its permeability through the blood-brain barrier. Thus, it improves skeletal muscle tension, pupil constriction, decreases arterial blood pressure and heart rate, increases sweat and digestive juices secretion. The drug, after permeating the central nervous system, increases the cognitive functions, improving memory and the information reproduction process. Frequent side effects include headaches and stomachaches, insomnia, heart rhythm disturbances, visual disturbances, accelerated breathing, nausea, vomiting and diarrhea.

The above data were prepared on the basis of leaflets attached to pharmacological drugs. The drugs were administered by qualified medical personnel, therefore their overdose is unlikely. They may cause undesired effects, although not in everybody. Nevertheless, any suspected overdose and other side effects should always be reported to a doctor.

\section{Organization of research}

The experiment included three unit tests performed in one-week intervals between successive exposures. The studies differed only in the type of drug (Vigil, Nivalin) or placebo (control group) administered. The exposure to hypoxia was performed in a low pressure chamber located in the Military Institute of Aviation Medicine in Warsaw. The altitude profile was in accordance with the applicable standard contained in the "Instructions for training in hypoxia" (annex 3, profile 2), WIML, 2003. The experiments were carried out in the spring period (March - April) at unchanging and repetitive intervals. The research received a positive opinion from the Ethics Committee of the Military Institute of Aviation Medicine, in accordance with the requirements for conducting research involving human subjects.

\section{Participants}

The study was conducted with 13 healthy men (age: $24 \pm 2,5$ years; height: $179 \pm 7 \mathrm{~cm}$; body weight:
$80 \pm 8,43 \mathrm{~kg}$; BMl: $25 \pm 1.5 \mathrm{~kg} / \mathrm{m} 2)$ not previously acclimated to high altitudes. The participants were dressed in a summer field uniform, a cotton Tshirt, shorts, socks and sports shoes. Each of the subjects took part in a unit study three times (depending on the type agent of administered: Vigil, Nivali, placebo). All of them were tested in the same and repeatable laboratory conditions. The participants were qualified to participate in medical experiments by a special aviation and medical committee on the basis of the current medical examination results (specialist internal medicine, ophthalmology, laryngology, neurology, ECG, $E E G$, tonal audiometry, cardiopulmonary exercise test (CPX), blood and urine analytical tests) and occupational physician's opinion. In order to reduce the level of situational stress prior to the examination, all participants were acquainted with the course of the examination, low pressure chamber exposure and the physiological consequences of hypoxia on the body by a WIML aviation medicine practitioner conducting trainings in the conditions of high-altitude hypoxia.

\section{Running of the specific test procedure (fig. 2)}

Within 24 hours before the experiment, the participants maintained a specific activity, which together with a unit study (from 19.00 on the first day to 14.00 on the second day) lasted 32 hours. In order to increase the state of fatigue at night, the subjects performed certain psychophysical tasks under time pressure (according to a fixed schedule) with a break for an hour's nap in a sitting position (from $2.00 \mathrm{am}$ to $3.00 \mathrm{am}$ ). During the whole unit study, the participants went through 5 series of tests from A, B, C, D to E at 20.00, $8.00(10.00$ administration of the drug), $11.30,13.00,14.00$ respectively). They included psychophysiological measurements, subjective assessment of the state of thermal comfort in relation to the whole body (Bedford test) and subjective assessment of the degree of nuisance of physical work (Borg test), as well as assessment of the mood level (UMACL questionnaire). During each unit study, core body temperature (Tc), heart rate (HR), energy expenditure (Kcal), weight loss (total sweat loss) and hydration (amount of fluid intake) were systematically monitored. At the same time (10.00 a.m. on the second day), a single dose of a specified pharmacological agent was administered to each participant at the same time. At 13.00 they began their exposure in the low low-pressure chamber (5000 $\mathrm{m}$ a.s.l.) (fig. 3.). In advance, the instructor informed the participants about the course of 


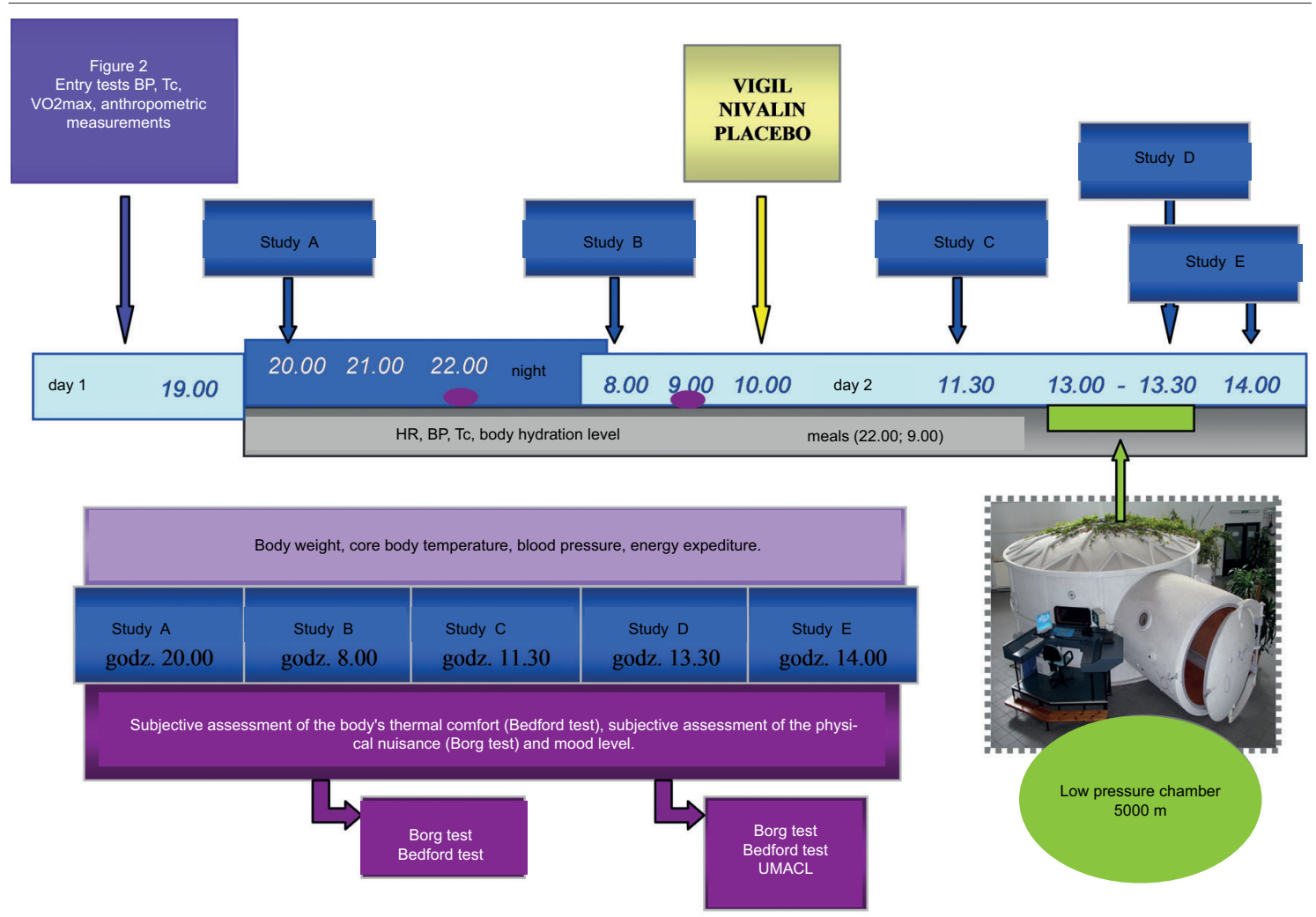

Fig. 2. Conduct of the unit study.

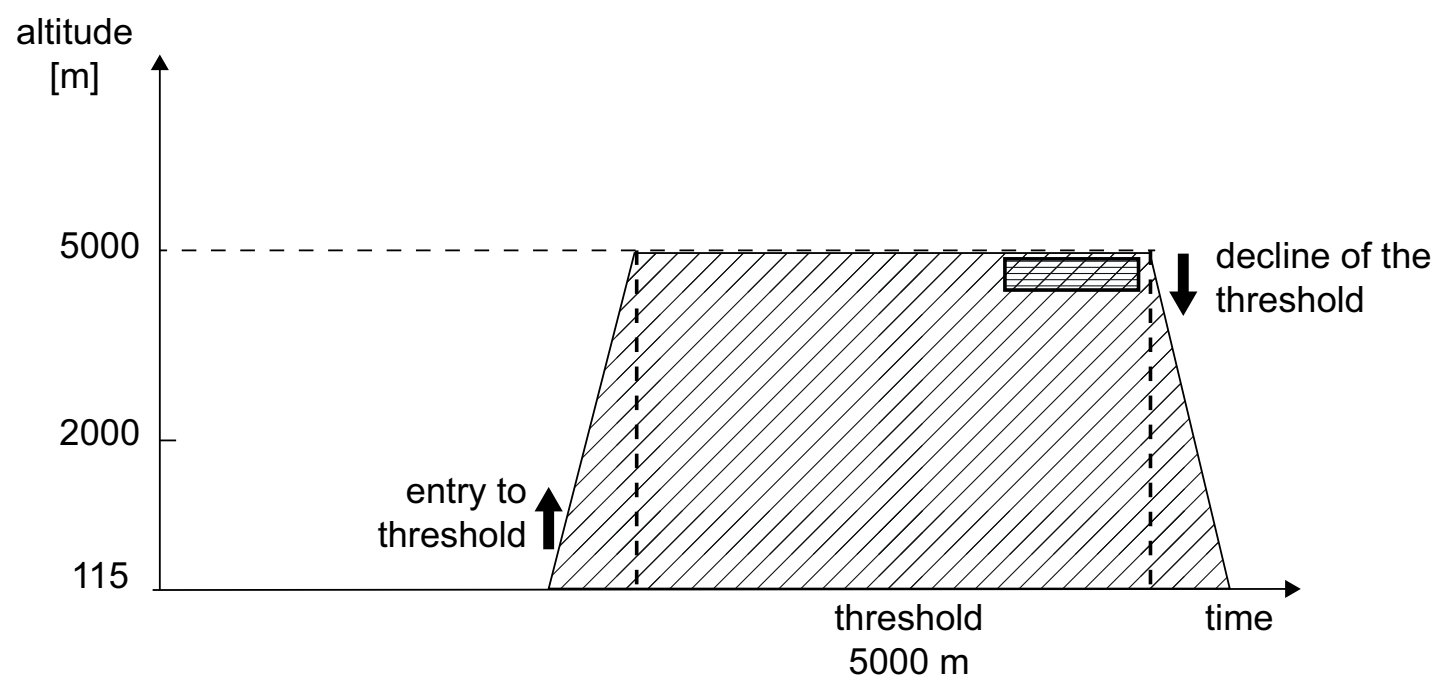

Fig. 3. Profile of exposure of the participant to high-altitude hypoxia in a low pressure chamber.

the test and the safety conditions (e.g. the middle ear pressure equalization technique and the use of the oxygen mask). Reaching the target altitude took place at an ascent speed of $0.5 \mathrm{mmHg} / \mathrm{s}$ and took 6-7 minutes. The stay at $5000 \mathrm{~m}$ a.s.l. (corresponding to a pressure of $405 \mathrm{mmHg}, 540 \mathrm{hPa}$ ) lasted 10 minutes. During exposure in the lowpressure chamber the heart rate (HR) and peripheral blood saturation level $(\mathrm{SaO} 2)$ were controlled.
The assessment of hypoxia tolerance was based on the time of decrease of arterial blood oxygen saturation to $\mathrm{SaO} 2=80 \%$ or reporting by the participant of discomfort, which determined putting on the oxygen equipment. The return to normobaric conditions took place at standard speed. The total duration of the single exposure lasted up to 25 minutes. 
Measurement of physiological parameters

During the whole examination, the following physiological parameters were monitored: core body temperature $\left[{ }^{\circ} \mathrm{C}\right]$ in the external auditory canal - using the Braun ThermoScan Pro 4000 thermometer, heart rate [bpm] - using the OMRON Intellisense M3 wrist device, energy expenditure [Kcal] - with the POLAR PULSOMETER RS400 heart rate monitor.

\section{Assessment of comfort and fatigue levels}

During the experiment, the participants subjectively assessed the thermal condition of the organism and the degree of nuisance of the work twice: in the B series of tests (before administration of the drug) and in the D series of tests (after administration of the drug and exposure in the low pressure chamber). The assessment of thermal comfort was carried out on the basis of Bedford's 7-point scale, which assumes that 1 - means "very cold" and 7 - means "very warm". The values between 3 - "pleasantly cool", 4 - "pleasant" and 5 "pleasantly warm" are within the range of thermal comfort. The assessment of the level of fatigue resulting from the degree of nuisance of physical work was made on the basis of a 12-point Borg scale assuming that 1 - means "very light work", 12 - means "very hard work".

\section{Evaluation of the emotional state of the participants}

In order to determine changes in the emotional state of the participants, the UMACL Adjective Mood Scale, used to assess mood understood as an affective experience of moderate duration (at least several minutes), was used. The UMACL scale consists of 29 positions in the form of adjectives.
The task of the person examined is to answer (yes, rather yes, rather not, definitely not) to what an extent each of the adjectives listed in the UMACL scale corresponds to their current mood. The assessment includes: energy stimulation (PE), voltage stimulation $(\mathrm{PN})$ and hedonistic tone $(\mathrm{TH})$.

\section{Statistical analysis}

StatSoft Polska STATISTICA 6.0 statistical package was used to analyze the results. Changes in psychophysiological parameters resulting from the administered pharmacological agents or placebo were assessed using the t-Student's parametric test for related variables. The results obtained in the B test at 8.00 (before administration of the drug) were compared with the results of the $E$ test at 14.00 (after administration of the drug and exposure in the low-pressure chamber). Statistical analysis was carried out on the increase values of psychophysiological parameters in the studied group of participants taking one of the pharmacological agents or placebo and was presented as mean $\pm S D$. The significance of the differences was assumed at the level of $p<0.05$.

\section{RESULTS}

\section{Physiological indicators}

The presented results constitute an analysis of physiological parameters data monitored and recorded in a series of tests $B$ and $E$ under conditions of alertness for 32 hours without the possibility of sleep in combination with the stimulus of high-altitude hypoxia (5000 $\mathrm{m}$ a.s.l.).

Core body temperature (fig. 4). In terms of core body temperature measurements (Tc), the following increments were record-

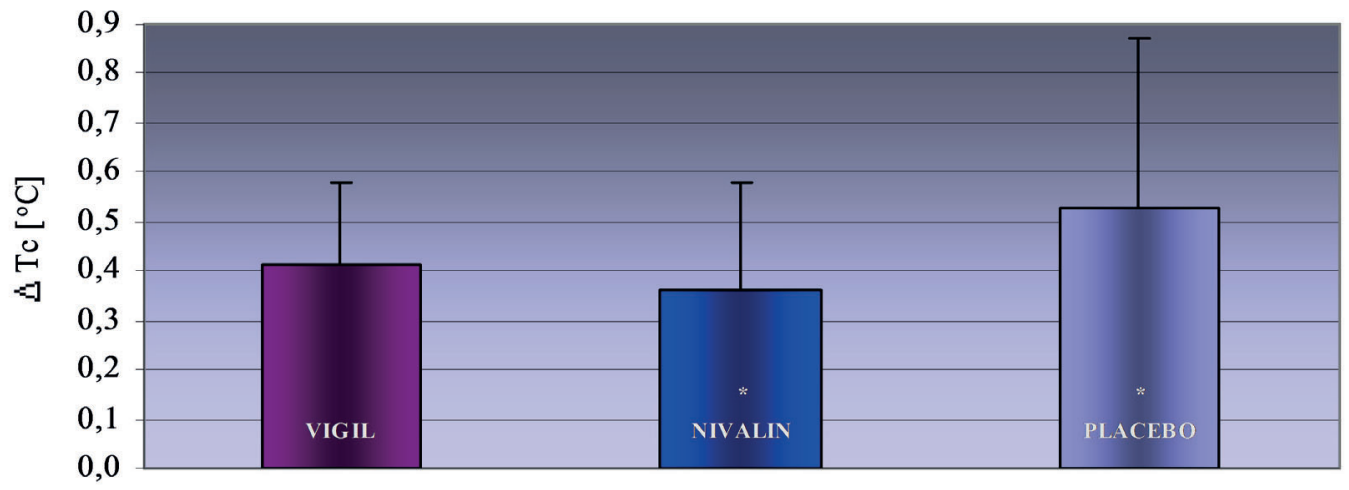

Fig. 4. Changes in the increase in internal body temperature $[\Delta T c]$ from the $B$ test - before administration of the drug to the $\mathrm{E}$ test - after finishing the exposure in the low-pressure chamber - $32 \mathrm{~h}$ of the state of alertness. 


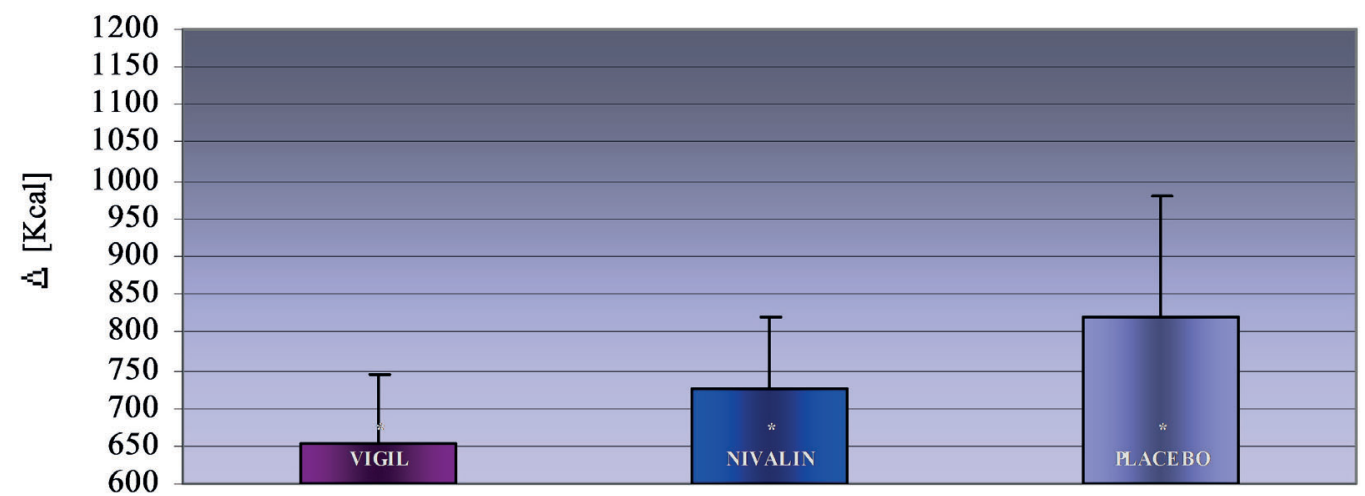

Fig. 5. Changes in the increase in energy expenditure $[\Delta \mathrm{Kcal}]$ from the $B$ test - before administration of the drug to the $\mathrm{E}$ test - after finishing the exposure in the low-pressure chamber $-32 \mathrm{~h}$ without sleep.

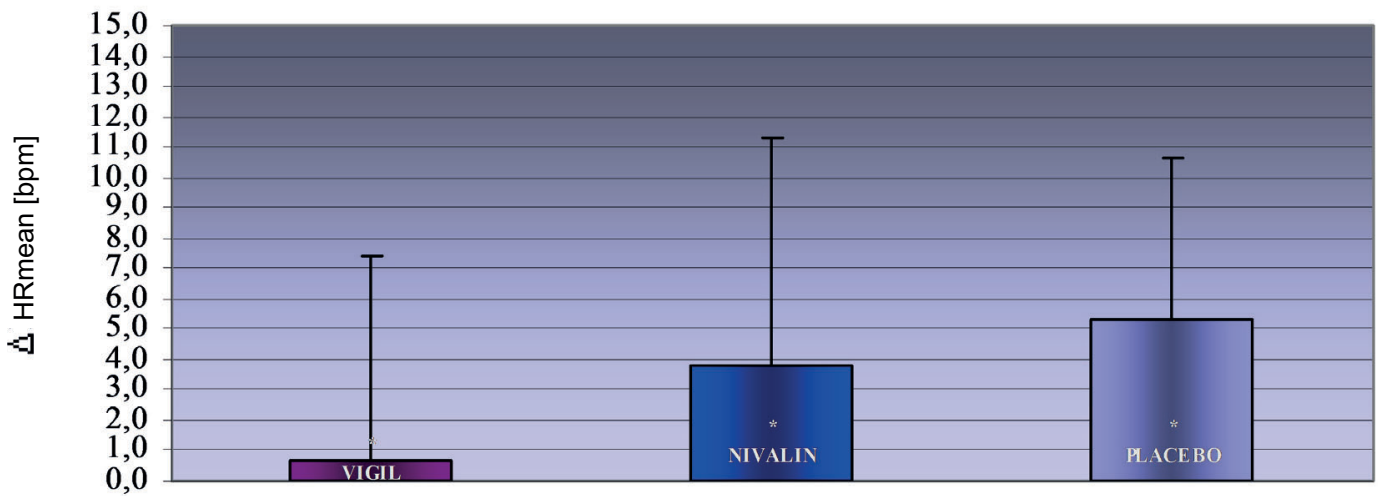

Fig. 6. Changes in the increase in heart rate ( $\triangle \mathrm{HR}$ Rmean) from the $B$ test - before administration of the drug to the $E$ test - after finishing the exposure in the low-pressure chamber $-32 \mathrm{~h}$ of alertness.

ed for Vigil $\triangle \mathrm{TCVIGIL}=0.41 \pm 0.17^{\circ} \mathrm{C}$ ), for Nivalin $\left(\triangle T\right.$ TCNIVALIN $\left.=0.36 \pm 0.22^{\circ} \mathrm{C}\right)$ and placebo $\left(\triangle \mathrm{TCPLACEBO}=0.53 \pm 0.37^{\circ} \mathrm{C}\right)$. Comparative analysis of the series of tests $B$ and $E$ showed the difference in Tc value changes at the level of statistically significant trend $(p<0.10)$ between the group receiving Nivalin and the control group (placebo).

Energy expenditure (fig. 5). Monitoring of energy expenditure in the group receiving Vigil showed changes at the level of $\Delta$ KcalVIGIL $=652.00 \pm 92.67$ and after using Nivalin $\Delta$ KcalNIVALIN $=725.00 \pm 94.96 \mathrm{Kcal}$, while in the placebo group this parameter reached $\triangle$ KcalPLA$C E B O=821.00 \pm 159.00$. Comparison of the energy expenditure increase in the case of Vigil and $\mathrm{Ni}$ valin compared to placebo showed a statistically significant difference $(p<0.05)$.

Total sweat loss. In the group taking Vigil this parameter was $\Delta \mathrm{VIGIL}=0.22 \pm 0.28 \mathrm{~kg}$, for Nivalin $\triangle$ NIVALIN $=0.26 \pm 0.32 \mathrm{~kg}$ and for placebo $\triangle \mathrm{PLA}$ $\mathrm{CEBO}=0.29 \pm 0.28 \mathrm{~kg}$. However, the differences recorded are not statistically significant.
Heart rate (fig. 6). The following changes of the parameter values were recorded using the heart rate monitor: in the group receiving Vigil, the average HR increase was $\Delta V I G I L=0.7 \pm 6.68 \mathrm{bpm}$, for Nivalin $\triangle$ NIVALIN $=3.8 \pm 7.49 \mathrm{bpm}$ and for placebo $\triangle \mathrm{PLACEBO}=5.3 \pm 5.31 \mathrm{bpm}$. The effect of administration of both drugs compared to placebo was statistically significant $(p<0.10)$.

\section{Subjective indicators of thermal comfort and workload}

Throughout the entire examination (32h), the participants have twice subjectively assessed the state of body thermal comfort on the Bedford scale and the level of fatigue on the Borg scale. The analysis was based on the results of the $\mathrm{E}$ series of tests obtained after administration of the drug and exposure in the low pressure chamber (32 $\mathrm{h}$ in the state of alertness). The group receiving Vigil rated the thermal comfort as BedfordVIG$\mathrm{IL}=4.25 \pm 0.75$ which corresponds to the "pleasant" feeling, the group receiving Nivalin at almost the 


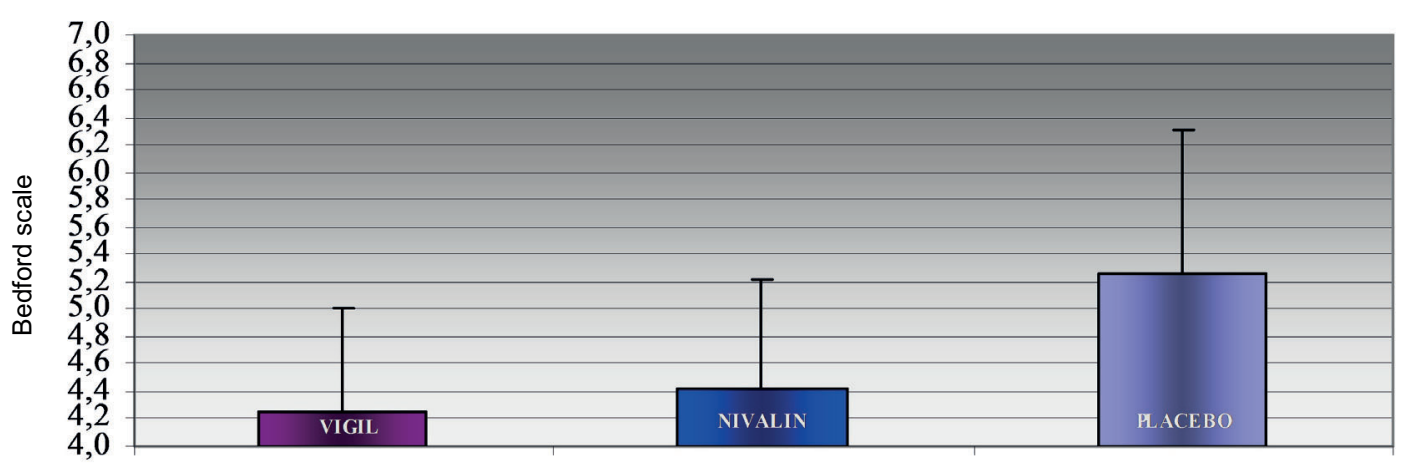

Fig. 7. Subjective assessment of the thermal comfort of the body (Bedford test) after administration of the drug and finishing the exposure in the low pressure chamber (5000 $\mathrm{m}$ a.s.I.) in 32 hours of the state of alertness (E test).

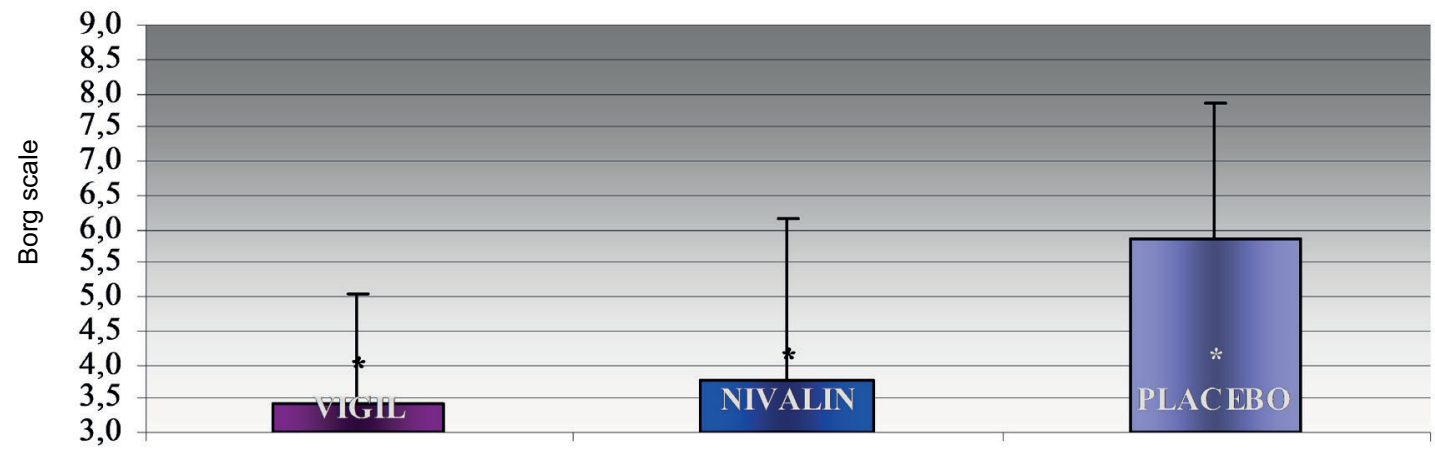

Fig. 8. Subjective assessment of the degree of nuisance of the physical work performed (Borg test) after administration of the drug and finishing of the exposure in he low pressure chamber ( $5000 \mathrm{~m}$ a.s.l.) in $32 \mathrm{~h}$ without the possibility of sleep (E test).

same level of Bedford NIVALIN $=4.42 \pm 0.79$ and the placebo group - Bedford PLACEBO $=5.25 \pm 1.06$ which corresponds to the "pleasantly warm" feeling. No statistically significant differences were found.

In terms of the assessment of the level of fatigue, people receiving Vigil described nuisance of the work as "moderately hard" Borg VIGIL $=3.42 \pm 1.62$, a comparable level was reached after administration of Nivalin Borg NIVALIN=3.75 \pm 2.37 , whereas in control conditions, the participants assessed the work as "hard" Borg PLACEBO=5.83 \pm 2.03 . Comparative analysis of Vigil and Nivalin against placebo showed statistically significant differences ( $p<0.05)$ (fig. 7 and 8 ).

\section{Assessment of high altitude hypoxia tolerance}

The analysis used two reliable indicators commonly used in aviation medicine: a) reserve time b) percentage of participants using oxygen equipment. The assessment of the influence of psychostimulants on the level of hypoxia was made in the 31 hour of the state of alertness (test $\mathrm{D}$ ). The measurement of the reserve time lasted until the critical level of arterial blood oxygen saturation $\mathrm{SaO} 2=80 \%$ was reached, which was equivalent to putting on the oxygen equipment. According to the Flight Regulations, saturation of $\mathrm{SaO} 2=80 \%$ is the level at which a pilot can operate flights without additional use of oxygen. The mean reserve time among participants taking Vigil was $\mathrm{tVIGI}=523 \pm 128 \mathrm{sec}$., Nivalin - tNIVALIN $=443 \pm 200 \mathrm{sec}$. and placebo - tPLACEBO=241 $\pm 225 \mathrm{sec}$. The second of the analyzed parameters was the percentage of participants using oxygen equipment. The following results were obtained in this respect: Vigil $=33 \%$ of participants, Nivalin $=42 \%$ of participants and placebo $=75 \%$ of participants. Statistical analysis showed that Vigil and Nivalin differed statistically significantly from placebo $(p<0.05)$ in terms of both parameters (fig. 9 and 10). 


\section{High altitude hypoxia tolerance $(5000 \mathrm{~m})$}

oxygen mask put in at $\mathrm{SaO} 2=80 \%$

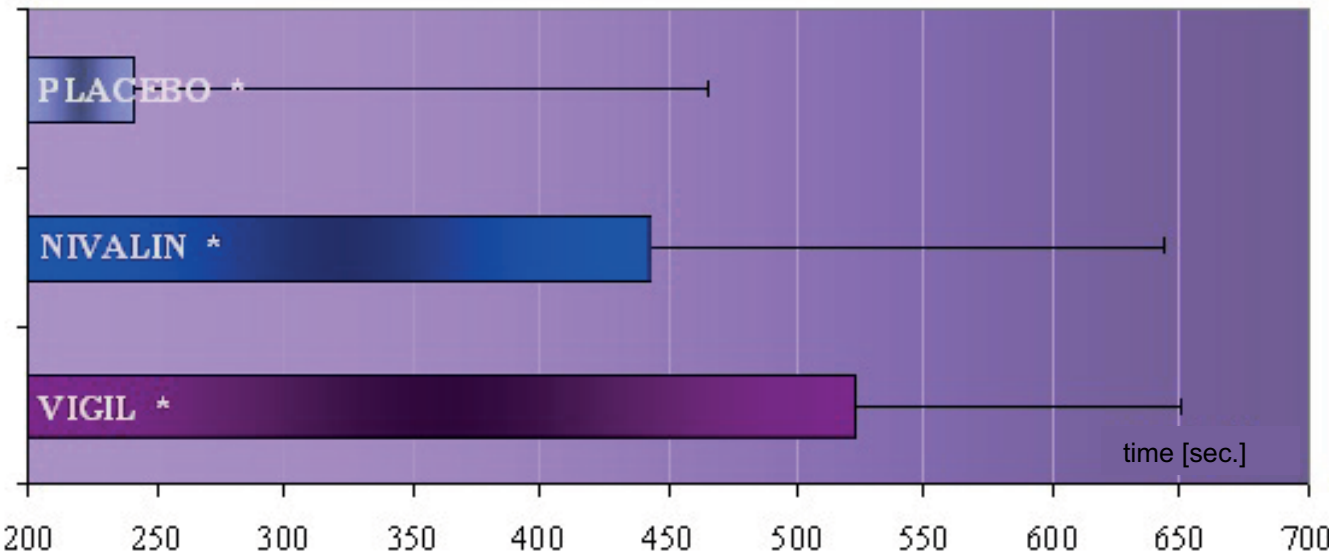

Fig. 9. Effects of the pharmacological agent used on the level of tolerance for high-altitude hypoxia (5000 m a.s.l.) based on the measurement of the reserve time during the exposure in a low-pressure chamber during 31 hours without sleep (D test).

High altitude hypoxia tolerance $(5000 \mathrm{~m})$

oxygen mask put in at $\mathrm{SaO} 2=80 \%$

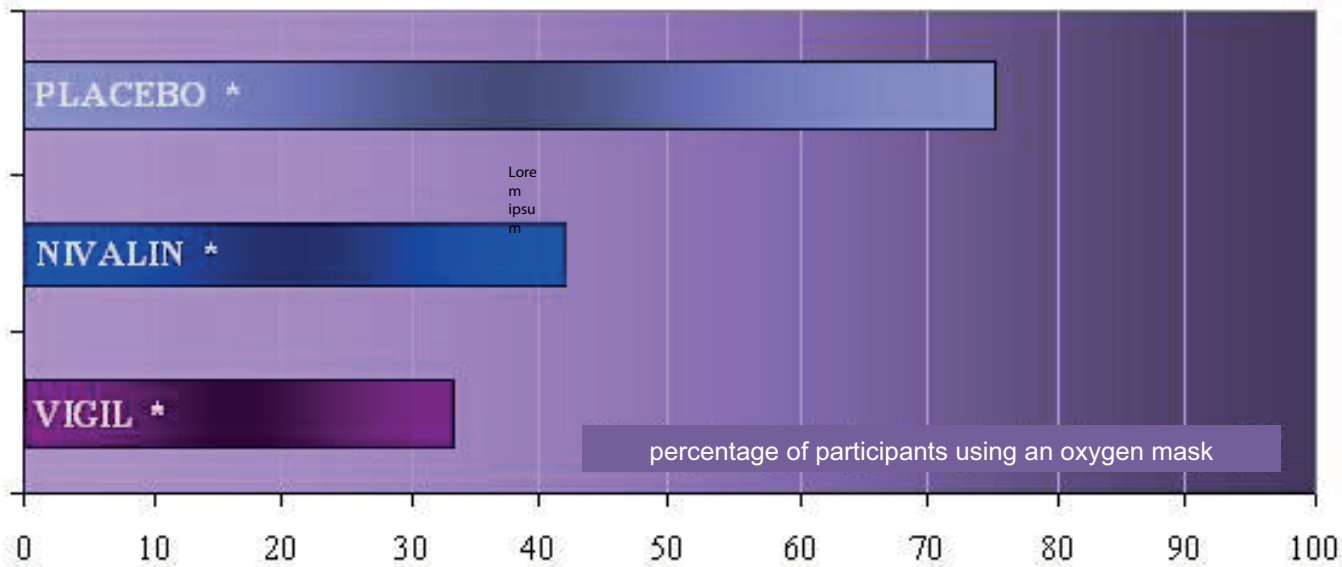

Fig. 10. Effects of the pharmacological agent used on the level of tolerance for high-altitude hypoxia (5000 $\mathrm{m}$ a.s.l.) expressed as the percentage of people using an oxygen mask during the exposure in the low-pressure chamber (evaluation after 31 hours of the state of alertness - D test).

\section{Assessment of the state of emotional excitation}

In the course of the unit study, participants evaluated their emotional state using the UMACL (Adjective Mood Scale) questionnaire in the $\mathrm{E}$ test series after administration of the drug and exposure to simulated conditions of high-altitude hypoxia. The following results were obtained with

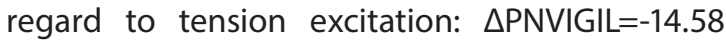
$\pm 6.66, \triangle$ PNNIVALIN $=-13.00 \pm 9.25, \triangle$ PNPLACE$B O=-11.41 \pm 9.82$. $A$ difference at the level of a statistically significant trend $(p<0.10)$ was found only between the groups taking Vigil and placebo. Analysis of the remaining values in terms of energy excitation and hedonistic tone showed no significant differences (fig. 11).

\section{DISCUSSION}

During their service, military pilots experience the necessity to undertake several hours long flight operations (sometimes during the night). This is associated with a significant extension of the period of alertness and constant keeping the 
(A)

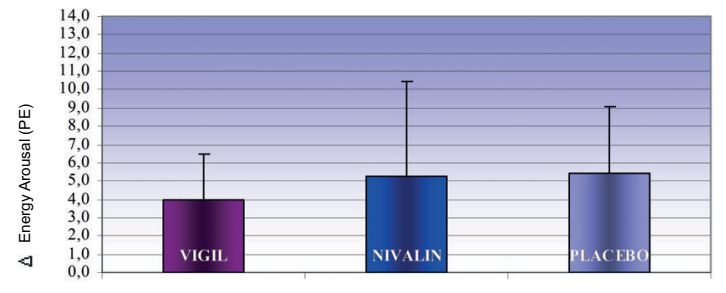

(B)

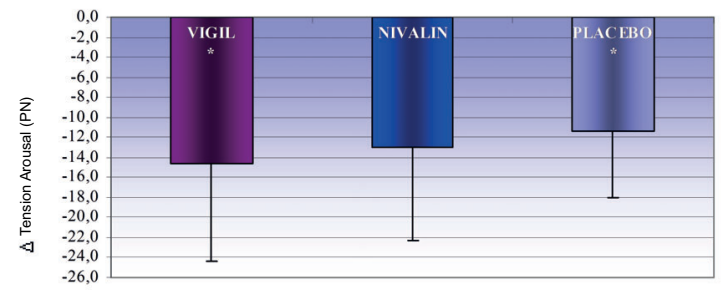

(C)

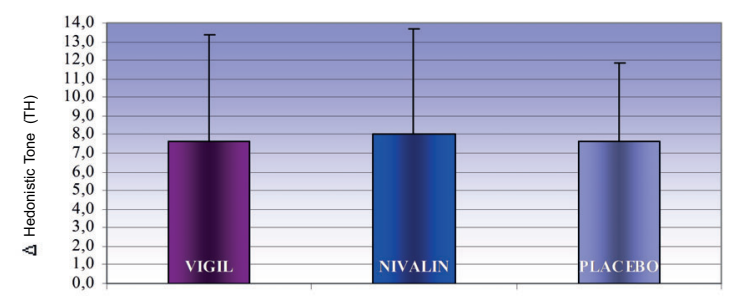

Fig. 11. The change in the emotional state of the participants determined on the basis of the UMACL questionnaire from test $B$ - before administration of the drug to test $\mathrm{E}$ - after administration of the drug and the exposure in the low-pressure chamber (32 $\mathrm{h}$ in the state of alertness). A - energy excitation (PE), $B$ - tension excitation (PN) and C - hedonistic tone $(\mathrm{TH})$.

ability to focus attention at a high level. Longterm continuation of such a complex activity without the possibility of sleep causes the excessive accumulation of psychophysical tensions and the deepening of fatigue, which significantly shortens the time of effective operation of a soldier.

Many of the harmful effects of fatigue have long been known and constitute a real problem in modern operational aviation. Although severe fatigue is a factor reducing a soldier's combat capabilities, its impact on the body is often neglected. In order to counteract the adverse effects of fatigue and improve tolerance to high-altitude hypoxia, research work has been undertaken on the military use of safe pharmacological agents. Conducting the tests will allow to determine whether the use of psychostimulants in the dose of the drug used by us will improve and optimize the psychophysical performance of military pilots in the conditions of prolonged combat tasks that make it impossible to regenerate the body using traditional methods (e.g.: sleep, rest, recreation, limiting the time spent in the combat zone).

Physiological indicators. Based on the results obtained from a series of tests from A to E carried out under the conditions of prolonged alertness for $32 \mathrm{~h}$ combined with 10-minute exposure to high-altitude hypoxia $(5000 \mathrm{~m}$ a.s.l., $405 \mathrm{mmHg}$, $540 \mathrm{hPa}$ ), a positive effect of both pharmacological agents with psychotropic properties was observed. The participants received Vigil at a dose of $100 \mathrm{mg}$ and Nivalin at a dose of $10 \mathrm{mg}$ or placebo. This effect was demonstrated by more beneficial changes in physiological parameters (with the indication of a stronger effect of Vigil): internal body temperature (Tc), energy expenditure (Kcal) and heart rate (HR) in relation to the control group (placebo).

In terms of the analysis of changes in the internal body temperature (measured in the external auditory canal), the smallest temperature gains were obtained after the application of Nivalin and slightly bigger in the group of participants taking Vigil and under control conditions (fig. 4). Nivalin limited the increase of the internal body temperature in relation to placebo at the level of a statistically significant trend $(p<0.10)$. Under the influence of Nivalin, changes in the body temperature during the unit study oscillated in the range closest to the physiological temperature. On this basis, it can be concluded that this agent was most effective in limiting the increase of the heat load on the body and the risk of exceeding the upper limit of $38^{\circ} \mathrm{C}$ recommended for crews of high-maneuver aircraft.

The analysis of data in terms of energy demand (fig. 5) for both psychostimulants showed that the caloric expenditure was significantly lower $(p<0.05)$ compared to the control group.

The highest total sweat loss (determined based on the change in naked body weight) (fig. 6) occurred as a result of administering placebo. However, the lowest amount of perspiration was achieved in the group of people using Vigil, slightly higher in the group taking Nivalin (differences between the groups were not significant). In the case of both drugs, lower sweating rate resulted in reduction of water balance disturbances and degree of dehydration as compared to placebo conditions.

A similar trend was observed in the control of heart rate (fig. 7). The results showed that the differences had an upward trend beginning with Vigil and Nivalin and reached the highest heart 
rate increases in the placebo group. Differences obtained for Vigil and Nivalin compared to placebo were changes at the level of a statistically significant trend $(p<0.10)$. Therefore, Vigil was the most effective in limiting heart rate increases. This indicates a slower rate of cardiovascular load increase and points to a slight improvement in heart rate and a reduction in the risk of disorders thereof. The American clinical trials on Provigil (modafinil) conducted by Cephalon Inc. based in Frazer (USA), published in 2018, confirmed the lack of adverse effects of this drug on cardiac indicators such as systolic and diastolic blood pressure and heart rate in healthy individuals [30]. Nevertheless, the risk of disorders in this area resulting from taking modafinil is known; therefore, this drug should not be taken by pilots with poorly controlled hypertension and past heart diseases [26].

Subjective indicators of thermal comfort and workload (level of fatigue). The aspect of subjective assessment of the state of thermal comfort of the whole body is an inseparable element in determining the influence of thermal conditions of the environment. The participants made their assessment in the B series of tests before administration of the drug and in the $E$ series immediately after exposure in the low pressure chamber, using the Bedford scale from 1 to 7 (respectively "very cold" - "very warm"). It was observed that the subjects after taking Vigil as well as Nivalin experienced a slight improvement in comfort, compared to the assessment obtained after taking placebo, where the vast majority of subjective opinions indicated a feeling of slight thermal discomfort. Both agents had a more favorable effect compared to the placebo group, although these differences were not significant. The direction of the changes indicates that people taking Vigil and Nivalin perceived the environmental conditions as thermoneutral and more comfortable in comparison to the control group (fig. 8).

All participants assessed subjectively the nuisance of physical activity (on a 12-point Borg scale) in a series of tests $B$ before administration of the drug and $\mathrm{E}$ immediately after exposure in a lowpressure chamber, i.e. after 32 hours of the state of continuous alertness. The assessment used is a simple method of evaluating the level of fatigue and perceived workload. As a result of the administration of both pharmacological agents, the subjective degree of nuisance of the work performed was lower than in control conditions assessed as "hard". These observations coincide with the direction and nature of changes in energy demand (fig. 5). The increase in the feeling of fatigue cor- related with the increased energy expenditure of the respondents. Therefore, it can be concluded that both Vigil and Nivalin significantly delayed the build-up of fatigue (feeling of workload) during a prolonged period of alertness ( $32 \mathrm{~h}$ without sleep), while the highest effort tolerance was achieved in the group receiving Vigil (fig. 9).

Assessment of high altitude hypoxia tolerance. The assessment of the degree of tolerance of simulated conditions of high-altitude hypoxia (5000 $\mathrm{m}$ above sea level) by the organism was performed on a group of people in a state of severe fatigue as a result of a prolonged period of alertness (after 31 hours). The mean reserve time was significantly longer in the group of people using Vigil and Nivalin than in the control group (fig. 10). Similar effectiveness and direction of changes of the administered drugs was observed in terms of the percentage of people using a mask to breath pure oxygen. In the groups taking pharmacological agents, significantly fewer participants used oxygen equipment than in control conditions. The results indicate that a single dose of Vigil (100mg) and Nivalin $(10 \mathrm{mg})$ significantly $(p<0.05)$ increased the time of resistance to oxygen deficiency and improved the body's tolerance to hypoxia (compared with the placebo test).

Assessment of the state of emotional excitation (mood). The emotional state of the pilot is an important factor in military and civil aviation. The dynamically changing situation during the flight combined with the time deficit requires from the crew members to be highly efficient in their actions, which is reflected in the instantaneous analysis and assessment of the position and decision making. Therefore, the activities carried out in the air are constantly accompanied by significant overload of the nervous system and fatigue resulting from high mental effort, strong emotions, frequent states of tension, anxiety, uncertainty caused by situational stress. Disturbances in the emotional state (e.g. reduced energy and hedonistic stimulation or excessive tension stimulation in relation to the optimal level) can often be accompanied by an impaired ability to concentrate, divide and shift attention. As a result, the risk of errors is increased due to a reduced ability to predict dangerous situations. In the mobility sphere, there may be incorrect, completely unintended movements or blocking of them. Chaotic action in a stressful situation can even lead to loss of control over the flight. Taking into account the fact that psychostimulants have a significant impact on the emotional state of a person, the participants were subjected to psychological tests. The level of emo- 
tional excitation was assessed based on a threedimensional well-being model in the form of an Adjective Mood Scale (UMACL questionnaire). The presented results of the examination (fig. 12) fitted into the model which included three correlated mood dimensions: energy excitation (PE) defined as energy to act, tension excitation (PN) reflecting anxiety-forming states, stress and hedonistic tone (TH) representing subjective feelings of pleasure or dissatisfaction. In the study, both drugs used had a beneficial effect on the stress level. The most effective in reducing emotional tension was Vigil, with Nivalin working slightly less well. However, no significant effect of the applied pharmacological agents was observed on the deterioration of mood in terms of energy excitation and hedonistic tone in relation to the values obtained in the control group. The emotional state observed among our participants indicated good mood and positive attitude as a result of taking psychoactive substances. The observed effect of psychostimulants in this aspect may result from a lower drug dose (100mg of Vigil) than, for example, in a clinical trial (2018) on Provigil by Cephalon Inc. With a dose of 200, 300 and $600 \mathrm{mg}$, patients experienced mood deterioration, fear and anxiety (30). Similarly, a study by Caldwell et al. (2004) showed that Vigil (Modafinil) (administered in three separate doses of $100 \mathrm{mg}$ each) resulted in a decrease in mood and perception, but this decrease was slowed down in relation to placebo while effectively reducing fatigue [7]. Therefore, in terms of assessing the impact of psychotropic drugs on the emotional state, more detailed research should be conducted to verify the final effect of psychostimulants on the human body.

To sum up, it can be concluded that a single dose of Vigil $(100 \mathrm{mg})$ and Nivalin $(10 \mathrm{mg})$ administered in a state of severe fatigue in conditions of many hours of mental and physical activity (about 32 hours) in combination with the stimulus of highaltitude hypoxia had a beneficial effect on human psychomotor performance in terms of assessment of physiological parameters important in aviation medicine (heart rate, internal body temperature, energy expenditure, total sweat loss). Both of the administered pharmacological agents improved subjective feelings both in terms of the degree of nuisance of the work performed and the thermal comfort of the body. In conditions of long-term sleep deprivation, the agents did not result in deterioration of the mood, including the state of excitation, which is essential for safe performance of tasks. Under simulated conditions of hypoxia (5000 m a. s.l.), Vigil and Nivalin, compared to pla- cebo, significantly reduced the decrease in oxygen deficiency and thus significantly increased the tolerance for high-altitude hypoxia. On the basis of analyzed changes in psychophysiological parameters, it can be concluded that both psychostimulants administered have a positive effect with a greater indication on the beneficial effect of Vigil, which at the same time suggests the preference of Vigil over Nivalin in long-term flights.

In connection with the successful effect of short-term stimulants on a fatigued body, it is worth discussing the possibility of their military use to counteract the decrease in psychophysical fitness (including fatigue) of flight crew members. However, it should be clearly emphasized that these pharmacological agents should only be used under medical supervision and only temporarily to postpone the harmful effects of fatigue until operational conditions allow normal rest and recovery (in the form of sleep or nap). This recommendation is aimed at ensuring the safety of a soldier-pilot while on duty due to the possibility of drug overdose, addiction or potential side effects.

\section{CONCLUSIONS}

Based on the results of the tests carried out with two pharmacological stimulants, it was concluded that:

1. Single doses of Vigil $(100 \mathrm{mg})$ and Nivalin (10mg) significantly improve the body's tolerance to high-altitude hypoxia (5000m a.s.l.) during 31 hours of alertness (compared to the control group - placebo).

2. In conditions of long-term sleep deprivation (32 hours) combined with the stimulus of high-altitude hypoxia, both psychostimulants slightly improve the subjective assessment of thermal comfort.

3. Both pharmacological agents significantly reduce the subjective degree of nuisance of the work performed, thus reducing the rate of fatigue and workload build-up.

4. The psychostimulants administered do not significantly affect mood level changes and therefore do not contribute to the occurrence of disorders in the emotional sphere of the pilot.

5. During a prolonged period of alertness Vigil and Nivalin favorably reduce the physiological load on the body: they reduce the increase in heart rate, improve thermoregulatory function (core body temperature) and reduce energy demand. 


\section{ACKNOWLEDGMENTS}

We extend our gratitude to nurses Agnieszka Kołodziej and Marzenna Starczewska for performing the test procedure, their role in selecting the research group and collecting materials required for our study. The authors thank Artur Przewodzki,
Tadeusz Kowalczyk and Marian Mikusek, the Department of Simulator Studies and Aeromedical Training team, technical experts with relevant knowledge and all volunteers taking part in our study for their hard work.

\section{AUTHORS' DECLARATION:}

Study Design: Joanna Łaszczyńska; Data Collection: Anna Przewodzka, Anna Czerwińska; Statistical Analysis: Anna Przewodzka, Anna Czerwińska; Manuscript Preparation: Anna Przewodzka, Anna Czerwińska. Funds Collection: Joanna Łaszczyńska. The Authors declare that there is no conflict of interest.

\section{REFERENCES}

1. Allan JR, Harrison MH, Higenbottam C, Ridgen R, Saxton C. In-flight thermal data from Harrier, Phantom, Buccaneer, Gazelle and Scout aircraft. Farnborough: IAM, RAF. 1976.

2. Allnutt MF, Allan JR. The effects of core temperature elevation and thermal sensation on performance. Ergonomics. 1973; 16(2):189-196.

3. Ballas CA, Kim D, Baldassano C, Hoeh N. Modafinil: past, present and future. Expert Rev. Neurother. 2002; 2(4):449-457.

4. Baranski JV, Pigeau R. A Self-monitoring cognitive performance during sleep deprivation: Effects of modafinil, d-amphetamine and placebo. Journal of Sleep Research. 1997; 6(2):84-91.

5. Billingham J, Jones L. The heat problem in aircraft of the Middle East Air Force. Farnborough: IAM, RAF. 1957.

6. Blockley WV, MacCutcheon JW, Lyman J, Taylor CL. Human tolerance for high temperature aircraft environments. Journal of Aviation Medicine. 1954; 25(5):515-22.

7. Caldwell JA, Caldwell JL, Smith JK, Brown DL. Modafinil's effects on simulator performance and mood in pilots during $37 \mathrm{~h}$ without sleep. Aviation Space and Environmental Medicine. 2004; 75(9):777-784.

8. Caldwell J.A. An overview of the utility of stimulants as a fatigue countermeasure for aviators. Brooks City-Base. TX: U.S. AFRL. 2003.

9. Caldwell JA, Caldwell JL, Brown DL. The effects of 37-hours of continuous wakefulness on the physiological arousal, cognitive performance, self-reported mood, and simulator flight performance of F-117A pilots. Brooks City-Base, TX: U.S. AFRL. 2003.

10. Caldwell JA. Efficacy of stimulants for fatigue management: the effects of Provigil and Dexedrine on sleep-deprived aviators. Transportation Research Part F: Traffic Psychology and Behaviour. 2001; 4(1):19-37.

11. Caldwell JA, Caldwell JL, Smythe NK, Hall KK. A double-blind, placebo-controlled investigation of the efficacy of modafinil for sustaining the alertness and performance of aviators: a helicopter simulator study. Psychopharmacolog. 2000; 150:272-282.

12. Caldwell JA, Mallis MM, Caldwell JL, Paul MA, Miller JC, Neri DF. Fatigue countermeasures in aviation. Aviat Space Environ Med. 2009; 80(1):29-59.

13. Cornum R, Cornum K, Caldwell JA. Stimulant use in extended flight operations. Airpower Journal. 1997; 11(1):53-58.

14. Dinges DF, Broughton RJ. Sleep and alertness: Chronobiological, behavioral, and medical aspects of napping. New York: Raven Press. 1989.

15. Guardiera S, Schneider S, Noppe A, Strüder HK. Motor performance and motor learning in sustained $+3 \mathrm{Gz}$ acceleration. Aviation Space and Environmental Medicine. 2008; 79(9):852-859.

16. Harrison MH, Higenbottam C, Rigby RJ. 8. Relationship between ambient, cockpit and pilot temperatures during routine air operations. Aviation Space and Environmental Medicine. 1974; 9(1):5-13.

17. Joy RJT. Heat stress in army pilots flying combat missions in the Mohawk aircraft in Vietnam. Aerospace Medicine. 1967; 38(9):895-900. 
18. Kenagy DN, Bird CT, Webber CM, Fischer JR. Dextroamphetamine use during B-2 combat mission. Aviation Space and Environmental Medicine. 2004; 75 (5):381-386.

19. Killgore WDS, Killgore DB, Day L, Li C, Kamimori GH, Balkin TJ. The effects of 53- hours of sleep deprivation on moral judgment. Sleep. 2007; 30(3):345-352.

20. Klopping W, Jonkman A, Valk P, Simons M. Efficacy of modafinil and caffeine to counteract hypnotic induce sleepiness during sustained operations. Neuilly-sur-Seine: RTO. 2005.

21. Lagarde D. Approche pharmacologique de la désynchronisation du rythme veille-sommeil en milieu militaire et sportif. Ann Pharm Fr. 2007; 65(4):258-264.

22. Liu Y, Wickens CD. Mental workload and cognitive task automaticity: an evaluation of subjective and time estimation metrics. Ergonomics. 1994; 37(11):1843-1854.

23. Monk TH. Shiftworker performance. Occupational Medicine: State of the Art. Reviews. 1990; 5(2):183-198.

24. Naitoh P, Kelly TL. Sleep management user's guide for special operations personnel. San Diego, CA: Naval Health Research Center. 1993.

25. Nicholson AN, Stone BM, Turner C. Drugs and Air Operations. Farnborough: Centre for Human Sciences, Defence Evaluation and Research Agency. 2001.

26. Ooi T, Wong SH, See B. Modafinil as a stimulant for military aviators. Aerosp Med Hum Perform. 2019; 90(5):480-483.

27. Pandit R. IAF pilots pop pills to get fighting edge. The Times of India. 2018 Feb. 8. [Accessed Nov. 2018]. Available from https://timesofindia.indiatimes. com/city/delhi/IAF-pilots-pop-pills-to-get-fighting-edge/articleshow/ 50894363.cms.

28. Petrie KJ, Powell D, Broadbent E. Fatigue self-management strategies and reported fatigue in international pilots. Ergonomics, 2004; 47(5):461-468.

29. Pigeau RA, Naitoh P, Buguet A. Modafinil, d-amphetamine and placebo during 64 hours of sustained mental work. I. Effects on mood, fatigue, cognitive performance and body temperature. Journal of Sleep Research. 1995; 4(4):212-228.

30. Provigil (modafinil). Frazer (PA): Cephalon, Inc.; [Accessed Nov. 2018]. Available from https://www.accessdata. fda.gov/ drugsatfda_docs/ label/2015/020717s037 s038lbl. pdf.

31. Sillami, N. Słownik psychologii. Katowice: Książnica. 1989.

32. Thirsk R, Kuipers A, Mukai C, Williams D. The space-flight environment: the International Space Station and beyond. CMAJ. 2009; 180(12):1216-1220.

33. Wesensten NJ, Belenky G, Kautz MA, Thorne DR, Reichardt RM, Balkin TJ. Maintaining alertness and performance during sleep deprivation: modafinil versus caffeine. Psychopharmacology (Berl). 2002; 159(3):238-247.

34. Wesensten NJ, Belenky G, Thorne DR, Kautz MA, Balkin TJ. Modafinil vs. caffeine: effects on fatigue during sleep deprivation. Aviat Space Environ Med. 2004; 75:520-525.

Cite this article as: Przewodzka A, Czerwińska A, Łaszczyńska J. Influence Of Selected Pharmacological Agents On The Psychophysical Efficiency Of A Human In Conditions Of The Extended Alert Period In Association With The Hypoxia Stimulus At High Altitude. Pol J Aviat Med Bioeng Psychol 2018; 24(4): 5-19. DOI: 10.13174/pjambp.25.05.2020.01 